\title{
PEMILIHAN LOKASI DAN PERENCANAAN SISTEM INTAKE AIR BAKU DI SUNGAI JAWI KECAMATAN SUNGAI KAKAP KABUPATEN KUBU RAYA
}

\author{
Dini Pangestu ${ }^{1)}$; Johnny MTS ${ }^{2)}$, Kiki Prio Utomo ${ }^{3)}$ \\ ${ }^{1}$ Program Studi Teknik Lingkungan, Universitas Tanjungpura, Pontianak \\ ${ }^{2}$ Program Studi Teknik Sipil, Universitas Tanjungpura, Pontianak \\ ${ }^{3}$ Program Studi Teknik Lingkungan, Universitas Tanjungpura, Pontianak \\ Email :pangestudine@yahoo.com
}

\begin{abstract}
ABSTRAK
Sungai Jawi merupakan salah satu sungai yang berada di Kecamatan Sungai Kakap Kabupaten Kubu Raya. Sungai Jawi memiliki dua muara, muara pertama bermuara di muara Kakap yang berhubungan langsung dengan Laut Natuna dan muara kedua bermuara di Sungai Kapuas, sehingga Sungai Jawi dipengaruhi oleh pasang surut air laut. Sungai Jawi digunakan oleh masyarakat sebagai sumber air baku dalam memenuhi kebutuhan sehari-hari. Tujuan dari perencanaan ini adalah untuk mendapatkan lokasi intake terbaik dari rambatan salinitas air asin yang masuk ke badan air Sungai Jawi agar dapat dimanfaatkan sebagai air bersih oleh masyarakat di Kecamatan Sungai Kakap khususnya warga Desa Pal XI, Sungai Kakap, Sungai Itik, Jeruju Besar, Sungai Kupah dan Sungai Rengas dengan merencanakan sistem intake untuk meminimalisasikan masuknya rambatan salinitas ke bangunan pengolahan pengambilan air baku (intake). Tahap pemilihan lokasi dan perencanaan sistem intake dimulai dengan pengujian kualitas air terutama parameter salinitas. Dilanjutkan dengan analisis kuantitas dan kontinuitas air baku serta perhitungan proyeksi kebutuhan air untuk 20 tahun perencanaan. Perhitungan proyeksi kebutuhan air digunakan untuk merencanakan kapasitas intake yang diperlukan. Lokasi terpilih untuk bangunan intake dengan nilai rambatan salinitas terendah berada di lokasi ketiga dengan jarak $10,22 \mathrm{~km}$ dari muara Kakap dengan kadar salinitas $0,00 \%$. Nilai DO pada saat pasang, surut dan hujan berturut turut 4,23; 3,53; 5,42. Nilai Kekeruhan (NTU) pada saat pasang, surut dan hujan berturut-turut $47 ; 29,93 ; 70,73$. Nilai $\mathrm{pH}$ pada saat pasang, surut dan hujan berturutturut 6,$4 ; 6,3 ; 5,7$. Nilai Suhu $\left({ }^{\circ} \mathrm{C}\right)$ pada saat pasang, surut dan hujan berturut-turut $31 ; 28 ; 25$. Debit air bersih untuk memenuhi kebutuhan hingga tahun 2030 adalah sebesar 306,56 L/detik. Sistem intake yang akan digunakan untuk membendung kebutuhan air baku adalah sistem long storage.
\end{abstract}

Kata kunci : sungai jawi, salinitas, intake

\begin{abstract}
Jawi River is one of the rivers in Sungai Kakap at Kubu Raya district. Jawi River has two estuaries, the first estuarie was at Kakap estuary which directly related to Natuna Sea and the second estuarie was at Kapuas river, so Jawi river have been in fluenced by tides of sea. Jawi River was used to be a peaple as a source of a raw water to filled their daily needs. The purpose of this plan is to get the best location of intake of the propagation from salinity of salt water into Jawi River water bodias in order to be used as a clean water to the people of Sungai Kakap district, especially the people of PaI XI village, Sungai Kakap, Sungai Itik, Jeruju Besar, Sungai Kupah and Sungai Rengas by planned intake system to minimize the salinity propagation of salt water enter the building of raw water treatment. Site selection and planning stage intake system was begun with testing water quality parameters, especially salinity. Continuing with the analysis of raw water quantity and continuitas and calculation of water demand projections for the 20-year planning. Calculation of water demand projections are used to plan the necessary intake capacity. Location chosen for building the intake with the lowest salinity value propagation in three locations with distance $10,22 \mathrm{~km}$ from estuary Kakap with salinity levels of 0,00\%. DO values at high tide, low tide and rain consecutive 4,23; 3,53;5,42. Value Turbidity (NTU) at high tide, low tide and rain respectively 47; 29,93; 70,73. PH value at high tide, low
\end{abstract}


tide and rain respectively 6,$4 ; 6,3 ; 5,7$. Value Temperature $\left({ }^{\circ} \mathrm{C}\right)$ at high tide, low tide and rain respectively 31; 28; 25 . Discharge water to meet the needs of up to 2030 amounted to $306,56 \mathrm{~L} / \mathrm{sec}$. Intake system that will be used to stem the need for raw water storage system is long.

Keywords : jawi river, salinity, intake

\section{Pendahuluan}

Sungai Jawi adalah saluran alami yang terletak diantara Kecamatan Pontianak Barat, Kecamatan Pontianak Kota dan Kecamatan Sungai Kakap (Kabupaten Kubu Raya) dimana pada bagian hilirnya adalah Kecamatan Sungai Kakap dan di Sungai Kapuas. Sungai Jawi mempunyai panjang $\pm 20 \mathrm{~km}$ yang dimanfaatkan oleh masyarakat sekitar sebagai sumber air baku untuk memenuhi kebutuhan sehari-hari.

Sungai Jawi dipengaruhi oleh pasang surut air laut karena memiliki dua muara, yaitu muara pertama di Laut Natuna, Kecamatan Sungai Kakap, Kabupaten Kubu Raya merupakan bagian Barat dari Sungai Jawi dan muara kedua di sungai Kapuas, Kecamatan Pontianak Barat merupakan bagian Timur dari Sungai Jawi. Saat ini, Sungai Jawi bagian Barat akan dimanfaatkan oleh PDAM Kabupaten Kubu Raya sebagai sumber air baku air bersih untuk Kecamatan Sungai Kakap dengan kapasitas intake sebesar 10 L/det dan belum beroperasi dengan letak intake sekitar $\pm 3 \mathrm{~km}$ dari muara Laut Natuna. Pada waktu pasang, air laut masuk melalui 2 muara sungai tersebut di atas (intrusi air asin). Proses ini menyebabkan kenaikan kadar garam dalam sungai. Pada akhirnya, akan berpengaruh pada kualitas air hasil pengolahan dan peralatan yang akan digunakan pada proses pengolahan air menjadi semakin mahal. Intrusi air asin masuk sampai jarak tertentu, sehingga masih mungkin dipilih lokasi baru untuk intake air bersih bila diketahui jauhnya intrusi air asin masuk. Agar sistem intake air bersih dapat beroperasi optimal perlu dikaji kemungkinan untuk memindahkan lokasi sistem intake dan membuat sistem intake baru di sungai ini sesuai dengan kondisi di lokasi terpilih. Maksud dari penelitian ini adalah untuk mengetahui laju besaran rambatan nilai salinitas yang di bawa oleh air laut. Tujuan penelitian ini adalah mendapatkan letak lokasi intake terbaik dengan cara mengetahui nilai rambatan air laut terkecil pada saat kondisi pasang, surut serta hujan.

\section{Metode Penelitian}

Penelitian dilakukan di Sungai Jawi yang terletak di Kecamatan Sungai Kakap, Kabupaten Kubu Raya. Dengan panjang sungai $\pm 13,23 \mathrm{~km}$ dan lebar rata-rata $\pm 14 \mathrm{~m}$, sampel air diambil pada 10 titik lokasi (Tabel 1). Parameter sampel yang diuji yaitu, Salinitas menurut Effendi (2003), Kekeruhan menurut KEPMENKES RI No: 416/MENKES/PER/IX/1990), DO, Suhu dan pH menurut (PP No. 82 tahun 2001). Waktu yang diperlukan untuk penelitian ini dimulai pada bulan Februari 2012 sampai dengan bulan Juni 2012. Penelitian ini dimulai dari survey awal (lokasi) terlebih dahulu, persiapan literatur dan dilanjutkan dengan pengujian kualitas air (meliputi penentuan lokasi sampling, pengambilan sampel dan perlakuan sampel), perhitungan kuantitas air, penentuan lokasi perencanaan, desain intake.

Tabel 1. Pengukuran Jarak Antar Lokasi

\begin{tabular}{|c|c|c|c|c|}
\hline No & Jarak (km) & Lokasi Penelitian & Koordinat & Kode Lokasi \\
\hline 1 & 0,00 & Parit Haruna & $00^{\circ} 02^{\prime} 38,03^{\prime \prime}$ LS; $109^{\circ} 16^{\prime}$ 58,42"BT & A1 \\
\hline 2 & 2,04 & Gg. Keluarga & $00^{0} 03^{\prime} 22,04^{\prime \prime}$ LS; $109^{0} 16^{\prime} 09,40^{\prime \prime} \mathrm{BT}$ & A2 \\
\hline 3 & 3,06 & Rumah orange & $00^{\circ} 03^{\prime} 41,20^{\prime \prime}$ LS; $109^{0} 15^{\prime} 42,60^{\prime \prime} \mathrm{BT}$ & A3 \\
\hline 4 & 4,08 & Mesjid Nurul Huda & $00^{0} 03^{\prime}$ 50,40" LS; $109^{\circ} 15^{\prime} 11,70^{\prime \prime} \mathrm{BT}$ & A4 \\
\hline 5 & 4,86 & Gg. Bersama & $00^{0} 03^{\prime}$ 57,40" LS; $109^{\circ} 14^{\prime} 47,00^{\prime \prime} \mathrm{BT}$ & A5 \\
\hline 6 & 5,88 & Parit Berembang & $00^{\circ} 04^{\prime}$ 01,10" LS; $109^{\circ} 14^{\prime} 14,40^{\prime \prime} \mathrm{BT}$ & A6 \\
\hline 7 & 6,90 & Alsintan & $00^{\circ} 04^{\prime} 03,40^{\prime \prime}$ LS; $109^{\circ} 13^{\prime} 41,51^{\prime \prime} B T$ & A7 \\
\hline 8 & 7,86 & Jembatan Punggur & $00^{\circ} 04^{\prime} 03,40^{\prime \prime}$ LS; $109^{0} 13^{\prime} 11,00^{\prime \prime} \mathrm{BT}$ & A8 \\
\hline 9 & 10,20 & PDAM & $00^{0} 03^{\prime} 31,90^{\prime \prime}$ LS; $109^{0} 12^{\prime} 04,40^{\prime \prime} \mathrm{BT}$ & A9 \\
\hline 10 & 13,28 & Muara Kakap & $00^{\circ} 03^{\prime} 47,56^{\prime \prime}$ LS; $109^{\circ} 10^{\prime} 38,33^{\prime \prime} \mathrm{BT}$ & A10 \\
\hline
\end{tabular}


Setelah didapatkan lokasi terbaik, Sungai Jawi ini diharapkan dapat memenuhi kebutuhan air bersih di Kecamatan Sungai Kakap khususnya pada 6 Desa yang direncanakan akan dilayani air bersih dengan memperhatikan syarat-syarat mutu air bersih.

\section{a. Pengumpulan Data}

- Data Primer : informasi daerah perencanaan, data parameter kualitas air baku dari hasil pemeriksaan uji di laboratorium dan debit air sungai. Pengukuran dilakukan pada saat air surut terendah dan pasang tertinggi, pada tanggal 11 Mei 2012 dan pengukuran pada saat hujan dilakukan pada tanggal 21 Mei 2012. Pada tanggal 11 Mei 2012, surut terendah terjadi dimulai pada jam 11.00 - 13.00 WIB dan pasang tertinggi terjadi dimulai pada jam 21.00-23.00 WIB.

- Data Sekunder : data statistik (data kependudukan dan gambaran umum lokasi studi), data pasang surut sungai (didapat dari TNI Angkatan Laut Kota Pontianak) dan peta batasan Sungai jawi di Kecamatan Sungai Kakap.

\section{b. Prosedur Pengambilan Sampel Air}

- Pengukuran Salinitas (kadar garam), DO, Kekeruhan, pH dan Suhu dilakukan pada tiga kondisi yaitu, pada saat surut terendah, pasang tertinggi dan hujan.

- Metode yang digunakan dalam pengambilan sampel untuk Salinitas (kadar garam), DO, Kekeruhan, pH dan Suhu adalah Metode Grab Sample (sampel sesaat).

- Untuk sampel Salinitas (kadar garam) dilakukan pengambilan masing-masing pada titik kedalaman 0,$2 ; 0,6: 0,8$ dari kedalaman sungai mengikuti kedalaman pada saat pengukuran kecepatan. Hal ini untuk memgetahui besarnya nilai rambatan salinitas pada kedalaman tersebut.

\section{c. Analisis Data}

- Menganalisis Kuantitas/Kebutuhan Air

$>$ Proyeksi Jumlah Penduduk

Proyeksi jumlah penduduk dapat dihitung dengan beberapa metode menurut NSPM KIMPRASWIL Tahun 2002, antara lain:

$\checkmark$ Arithmatic Rate of Growth Methode

$$
P n=P o(1+R n)
$$

\section{Geometric Rate of Growth Methode}

$$
P n=P o(I+r)^{n i}
$$

$\checkmark$ Least Square Rate of Growth Methode

$$
\begin{aligned}
& \mathrm{Y}=\mathrm{a}+\mathrm{bx} \\
& a=\frac{\sum Y \cdot \sum X^{2}-\sum Y \cdot \sum X Y}{n \cdot \sum X^{2}-\left(\sum X\right)^{2}}, b=\frac{n \sum X \cdot Y-\sum X \cdot \sum Y}{n \cdot \sum X^{2}-\left(\sum X\right)^{2}}
\end{aligned}
$$

$>$ Perhitungan Kebutuhan Air

$\checkmark$ Kebutuhan air untuk domestik, yaitu kebutuhan air untuk rumah tangga.

$\checkmark$ Kebutuhan air untuk non domestik (industri, sosial, pendidikan, perkantoran, peribadatan dan lain sebagainya). Untuk menentukan besarnya kebutuhan air 
domestik, yaitu dengan cara : jumlah pemakaian air $\mathrm{x}$ jumlah penduduk. Sedangkan untuk menentukan besarnya kebutuhan air non domestik, yaitu dengan cara : jumlah pemakaian air x jumlah unit. Standar kebutuhan air dihitung berdasarkan Ditjen Cipta Karya Departemen PU tahun 2000.

\section{- Menganalisis Kontinuitas/Ketersediaan Air}

Untuk mengetahui data debit sungai tersebut dapat dihitung secara analitis, diukur secara langsung dengan menggunakan alat ukur Current Meter.

\section{- Menganalisis Kualitas Air}

Untuk mengetahui kualitas air di sungai diperlukan data kualitas air Sungai Jawi yang didapatkan dari hasil pengamatan dan pengujian air.

\section{- Menganalisis Letak dan Jenis Intake}

Informasi yang harus dimiliki dalam menganalisis letak intake adalah kadar garam terendah di lokasi terpilih, kualitas air baku yang sesuai dengan standar baku mutu Kelas Satu, ketersediaan air di lokasi dapat memenuhi jumlah kebutuhan air masyarakat serta kontinuitas air sungai. Sedangkan informasi yang harus diketahui dalam menganalisis jenis intake, yaitu : kedalaman dasar sungai rata-rata, lebar sungai, keadaan debit sungai.

\section{d. Tahap Perencanaan Sistem Intake}

Sistem pengambilan intake menggunakan intake jembatan dengan menambahkan sumur di ujung pipa penghisap. Fungsi sumur agar tetap bisa mengambil air baku walau pada saat kondisi air sungai surut.

\section{Hasil dan Pembahasan}

\section{A. Pengukuran Kualitas Air Sungai Jawi}

\section{a. Salinitas}

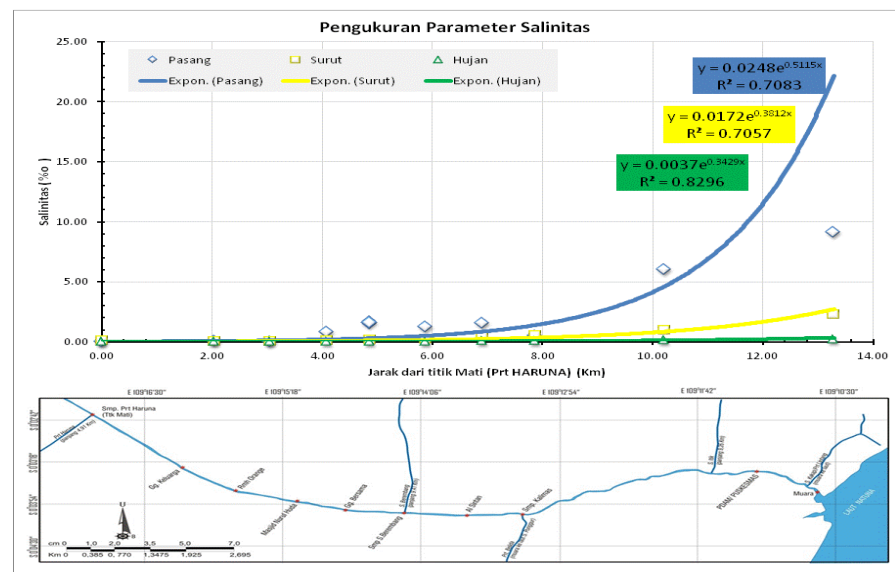

Gambar 1. Hasil Pengukuran Parameter Salinitas

Dari gambar 1. di atas, dapat dilihat keadaan salinitas pada saat kondisi air pasang di Sungai Jawi yang ditunjukkan dengan warna biru. Pada saat pasang, dorongan aliran dari laut masuk sejauh 10,22 km dari muara tepatnya berada di lokasi A3 dengan nilai salinitas $0,00 \%$. Air Sungai Jawi pada saat pasang dikategorikan air payau. Keadaan salinitas pada saat kondisi air surut di Sungai Jawi yang ditunjukkan dengan warna kuning. Rambatan salinitas pada saat surut masuk sejauh 10,22 km di lokasi A3 dengan nilai salinitas 0,00\% termasuk kategori air payau. Keadaan salinitas pada saat kondisi hujan di Sungai Jawi yang ditunjukkan dengan warna hijau. Pada tiap 
lokasi hasil salinitasnya mendekati nilai air tawar $<0,5 \%$.. Hal ini terjadi percampuran antara air hujan dengan air Sungai Jawi sehingga terjadi penetralan air yang dilakukan oleh hujan dari air asin menjadi air payau.

Dengan demikian, dapat disimpulkan bahwa lokasi terpilih untuk nilai salinitas terbaik/terendah berada di lokasi A3 dengan pertimbangan jarak dari muara 10,22 km dan nilai salinitas itu sendiri dilihat dari kondisi pasang, surut serta hujan nilai salinitasnya mendekati $0,00 \%$.

\section{b. Kekeruhan}

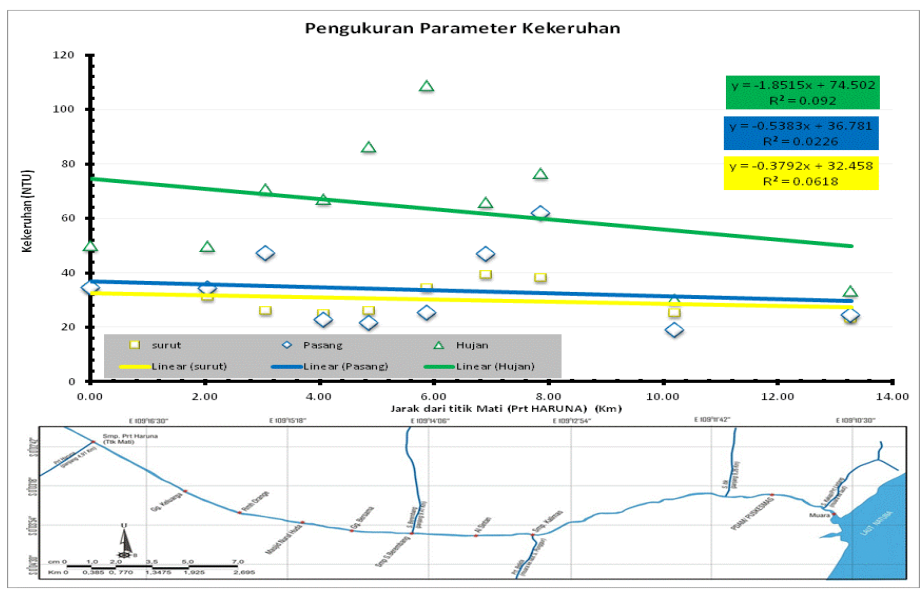

Gambar 2. Hasil Pengukuran Parameter Kekeruhan

Dari gambar 2 di atas, dapat dilihat nilai kekeruhan pada saat pasang yang ditunjukkan dengan warna biru. Tingginya nilai kekeruhan dimungkinkan pada saat pengambilan sampel air keadaan arus sungai pada saat pasang begitu kuat, sehingga mengakibatkan resuspensi sedimentasi di dasar sungai serta partikel lumpur terangkat ke permukaan. Kekeruhan juga bisa dipengaruhi oleh warna air sungai karena Kecamatan Sungai Kakap sebagian lahannya merupakan lahan gambut. Nilai kekeruhan saat kondisi pasang di setiap lokasi penelitian melewati batas yang diperbolehkan. Nilai kekeruhan pada saat surut yang ditunjukkan dengan warna kuning. Kekeruhan tinggi diakibatkan adanya masukan aliran dari sungai-sungai yang bermuara di Sungai Jawi sehingga pertemuan sungai ini mengakibatkan tingginya arus disekitar lokasi pengambilan sampel karena resuspensi sedimentasi di dasar sungai serta partikel lumpur terangkat ke permukaan seperti Sungai Berembang, Sungai Belida dan Parit Haruna. Kekeruhan tinggi diakibatkan juga tingginya aktivitas MCK masyarakat disekitar lokasi pengambilan sampel dan disebabkan juga adanya buangan limbah domestik ke badan air Sungai Jawi secara langsung dari masyarakat sekitar. Semakin ke muara nilai kekeruhan semakin rendah. Hal ini disebabkan karena adanya arus air laut yang masuk sehingga terjadi penambahan air di muara oleh air laut dan kekeruhan semakin berkurang. Nilai kekeruhan pada saat hujan yang ditunjukkan dengan warna hijau. Pada saat hujan kekeruhan menjadi lebih tinggi dari keadaan pada saat pasang maupun surut, hal ini terjadi karena lahan disekitar pengambilan sampel merupakan areal terbangun seperti pemukiman penduduk, pasar, pertokoan, kebun dan kondisi jalan yang masih berbentuk lapisan tanah, sehingga pada saat hujan terjadi pengikisan tanah oleh air hujan dan aliran permukaan langsung terbawa menuju ke sungai akibat tidak adanya penahan tanah dibagian hulunya. 


\section{c. DO (Dissolve Oxygen)}

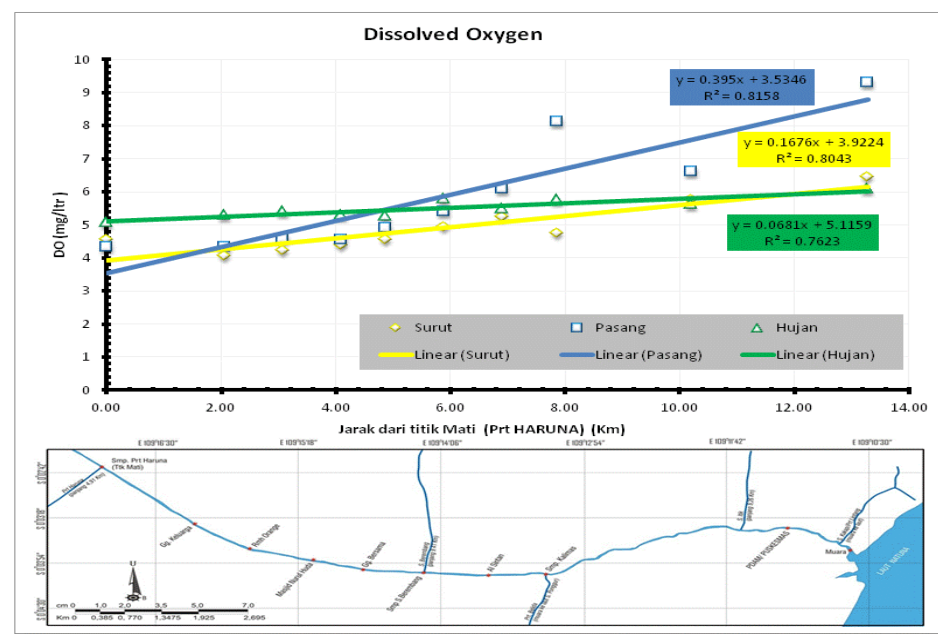

Gambar 3. Hasil Pengukuran Parameter Dissolve Oxygen

Dari gambar 3. diatas, nilai DO pada saat pasang ditunjukan dengan warna biru. Pengambilan pada saat pasang dilakukan pada malam hari. Rendahnya nilai DO disebabkan rendahnya aktivitas tanaman sungai yang berfotosintesis. Karena pada malam hari tidak terjadi fotosisntesis, oksigen yang terbentuk pada siang hari akan digunakan oleh ikan dan tumbuhan air, sehingga terjadinya penurunan konsentrasi oksigen secara drastis dan kecilnya arus sungai di lokasi pengambilan sampel juga ikut mempengaruhi rendahnya nilai $\mathrm{DO}$, sehingga kurangnya pertukaran oksigen di udara dengan di badan air. Semakin ke muara (A10) nilai DO semakin baik. Hal ini disebabkan kuatnya arus yang masuk ke dalam badan air Sungai Jawi sehingga mengakibatkan pertukaran udara menjadi besar. Pada saat pasang, nilai DO perairan badan air Sungai Jawi berada pada kisaran 4-10 mg/L. Nilai DO pada saat surut ditunjukan dengan warna kuning. Rendahnya nilai DO pada saat surut dikarenakan besarnya buangan limbah domestik yang dibawa oleh sungai-sungai yang bermuara di Sungai Jawi, seperti Sungai Berembang, Sungai Belida dan Parit Haruna. Serta tingginya kegiatan MCK yang dilakukan oleh masyarakat di tepi sungai, hal ini mempengaruhi jumlah oksigen terlarut di dalam badan air Sungai Jawi. Namun, untuk lokasi yang berada tidak jauh dari pertemuan dua buah arus, nilai DO mendekati normal. Sehingga terjadinya pertukaran oksigen yang baik. Pada saat surut, nilai DO perairan badan air Sungai Jawi berada pada kisaran $4-7 \mathrm{mg} / \mathrm{L}$. Nilai DO pada saat hujan ditunjukan dengan warna hijau. Pada saat kondisi hujan nilai DO pada masing-masing lokasi, rata-rata berkisar antara $5-6 \mathrm{mg} / \mathrm{L}$. Ini dikarenakan adanya pertukaran udara yang baik, yang dilakukan pada saat air hujan masuk ke dalam badan air Sungai Jawi, namun pada saat hujan nilai DO menjadi rendah dibandingkan dengan nilai DO pada saat pasang. Hal ini dikarenakan adanya sumbangan air yang membawa buangan limbah domestik dari parit-parit sekitar yang bermuara di Sungai Jawi. Walaupun nilai DO pada saat hujan tidak terlalu baik namun relatif mendekati ambang batas yang diperbolehkan.

\section{d. Suhu}

Suhu air mempunyai peranan dalam mengatur kehidupan biota perairan, terutama dalam proses metabolisme. Kenaikan suhu menyebabkan terjadinya peningkatan konsumsi oksigen, namun dipihak lain akan mengakibatkan turunnya kelarutan oksigen dalam air. Oleh karena itu, maka pada kondisi tersebut organisme akuatik setingkali tidak mampu memenuhi kadar oksigen terlarut untuk keperluan proses metabolisme dan respirasi (Effendi,2003). Pada saat pasang, surut serta hujan keadaan suhu di badan air Sungai Jawi berada pada rata-rata rentang $28,15{ }^{\circ} \mathrm{C}, 30,6{ }^{\circ} \mathrm{C}$ serta $25,8^{\circ} \mathrm{C}$ (lihat Gambar 4). Nilai ini masih berada pada rentang baku mutu Kelas Satu yang diijinkan. Dengan demikian Sungai Jawi dapat dimanfaatkan sebagai sumber air baku air bersih. 


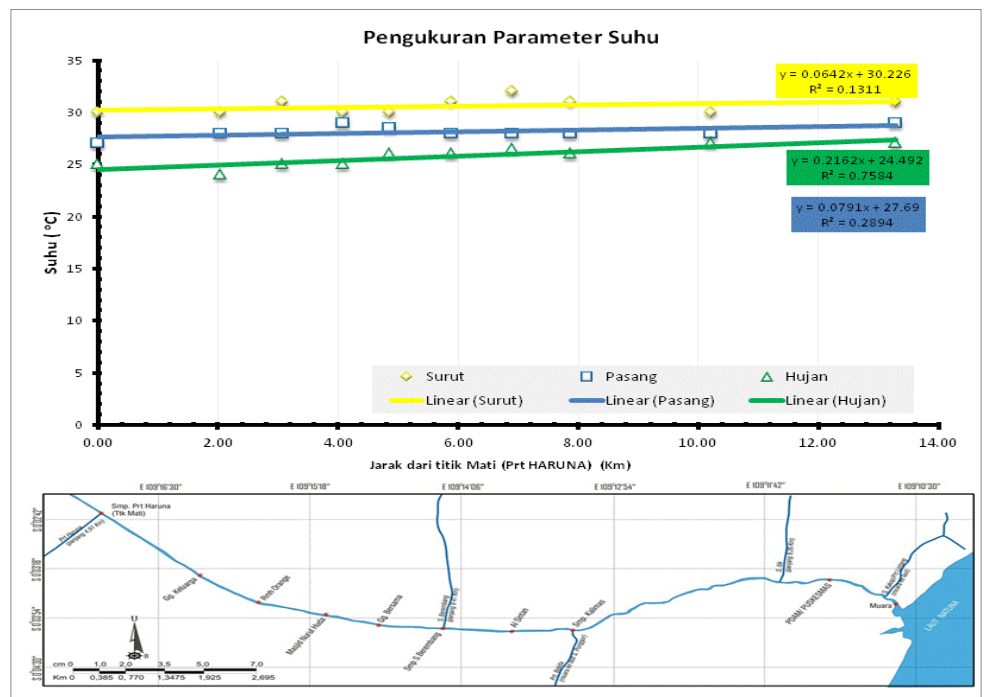

Gambar 4. Grafik pengukuran parameter suhu

e. $\mathrm{pH}$

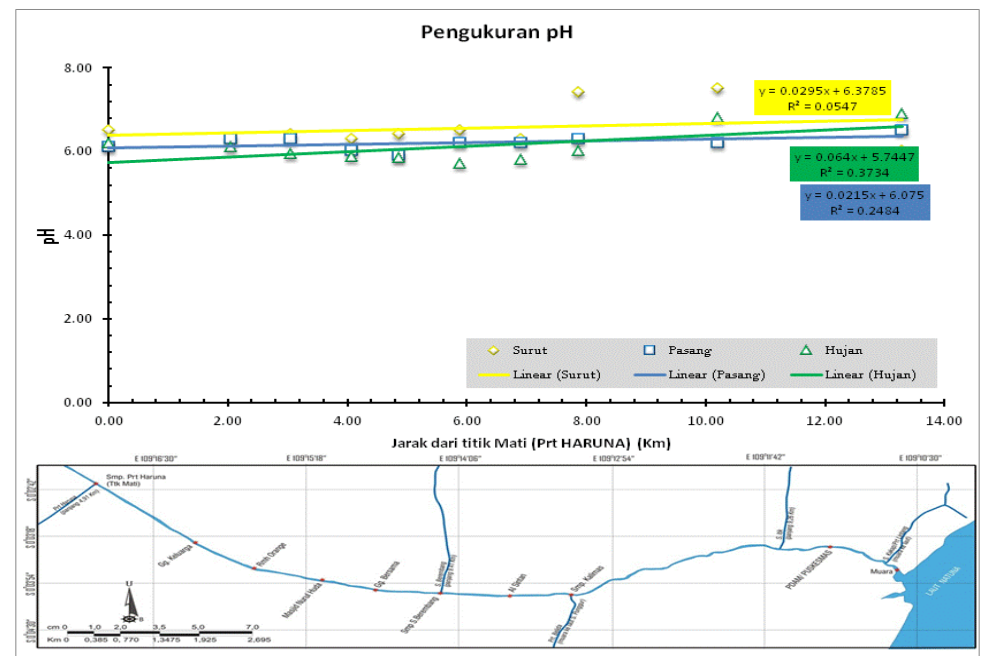

Gambar 5. Grafik pengukuran parameter $\mathrm{pH}$

Dari gambar 5. diatas, nilai pH pada saat pasang ditunjukan dengan warna biru dengan rata-rata nilai 6,20. Nilai $\mathrm{pH}$ pada saat surut ditunjukan dengan warna kuning dengan rata-rata nilai 6,55. Sedangkan, nilai pH pada saat hujan ditunjukan dengan warna hijau dengan rata-rata nilai 6,12. Nilai ini berada pada sifat asam, hal ini diakibatkan karena dasar sungai atau tanah di sungai ini merupakan tanah gambut, sehingga menurunkan nilai pH di perairan. Namun demikian, secara keseluruhan $\mathrm{pH}$ perairan Sungai Jawi masih berada pada kisaran yang aman digunakan sebagai sumber air baku air bersih berdasarkan ambang batas baku mutu kualitas air Kelas Satu yang mensyaratkan nilai pH antara 6-9 berada di kondisi cukup baik antara normal. Dengan demikian, pH perairan Sungai Jawi dapat mendukung kehidupan yang ada di dalamnya dan dapat digunakan sebagai sumber air baku air bersih.

\section{B. Proyeksi Kebutuhan Air Enam Desa Pelayanan}

Sistem intake air bersih di Kecamatan Sungai Kakap dirancang dengan umur rencana 20 tahun. Dengan menganggap tahun 2010 sebagai tahun awal perencanaan, maka dengan umur 20 tahun proyeksi kebutuhan air dibuat sampai tahun 2030. Proyeksi kebutuhan penduduk di enam desa pelayanan yang menjadi dasar dalam penentuan kebutuhan air dihitung dengan menggunakan rumus pertumbuhan geometrik. Metode geometrik dipilih berdasarkan nilai koefisien korelasi yang paling besar atau mendekati nilai satu dan standar deviasi paling 
kecil dengan membandingkan ketiga metode proyeksi yang ada, yaitu metode aritmatik, geometrik dan least square.

Total penduduk di enam desa yang akan dilayani pada tahun 2010 berjumlah 65.088 jiwa berdasarkan Kecamatan Sungai Kakap Dalam Angka Tahun 2011. Menurut Departemen Pekerjaan Umum, Direktorat Jenderal Cipta Karya Tahun 2000 kebutuhan air bersih penduduk untuk kategori Kota Kecil (IV), yaitu sebesar 100 liter per orang per hari sehingga dapat diketahui kebutuhan air penduduk per tahun.

Tabel 2. Proyeksi Penduduk dan Kebutuhan Air Domestik untuk 6 Desa hingga Tahun 2030

\begin{tabular}{|c|c|c|c|c|c|c|}
\hline \multirow{2}{*}{ No. } & \multirow{2}{*}{ KEGIATAN } & \multicolumn{5}{|c|}{ TAHUN } \\
\hline & & 2010 & 2015 & 2020 & 2025 & 2030 \\
\hline 1. & Jumlah Populasi (Jiwa) & 63.706 & 70.613 & 78.268 & 86.754 & 96.160 \\
\hline 2. & Total Kebutuhan Domestik (L/Hari) & $1.146 .708,00$ & 1.948 .914 .23 & $3.068 .124,78$ & $4.580 .619,11$ & $6.577 .330,52$ \\
\hline 3. & Total Kebutuhan Domestik (L/det) & 13,27 & 22,56 & 35,51 & 53,02 & 76,13 \\
\hline 4. & Total Kebutuhan Non Domestik (L/Hari) & $10.149 .240,00$ & $10.179 .061,25$ & $10.225 .923,05$ & $10.266 .686,62$ & $15.495 .292,95$ \\
\hline 5. & Total Kebutuhan Non Domestik L/det) & 117,47 & 117,81 & 118,36 & 118,83 & 179,34 \\
\hline & Kebutuhan Harian Total (Q total) (L/Hari) & $11.295 .948,00$ & $12.127 .975,48$ & $13.294 .047,82$ & $14.847 .305,73$ & $22.072 .623,48$ \\
\hline & Kebutuhan Harian Total (Q total) (L/det) & 130,74 & 140,37 & 153,87 & 171,84 & 255,47 \\
\hline & Kehilangan $\mathbf{2 0 \%}$ & 26,15 & 28,07 & 30,77 & 34,37 & 51,09 \\
\hline & butuhan Harian Maksimum (1,2 $\times$ Q tot) (L/det) & 156,89 & 168,44 & 184,64 & 206,21 & 306,56 \\
\hline & Kebutuhan Jam Puncak (1,75 x Q tot) (L/det) & 228,80 & 245,65 & 269,27 & 300,73 & 447,07 \\
\hline
\end{tabular}

\section{Analisis Kontinuitas Air}

Untuk memenuhi kebutuhan air masyarakat harus disesuaikan dengan berdasarkan ketersediaan debit air sungai yang ada. Hal ini perlu diperhatikan agar tidak terjadi kekurangan air bersih dikemudian hari. Kekurangan air bersih akan terjadi apabila kebutuhan air bersih melebihi ketersediaan air yang ada.

Pengukuran debit secara sederhana menurut dinas Pekerjaan Umum dapat menggunakan rumus (5), dimana pada saat pengukuran di lapangan dilakukan saat air sedang mengalami kondisi surut terendah di bulan Mei namun tidak dalam kondisi konda pada tanggal 11 Mei 2012 menurut data pasang surut yang di dapat dari TNI- AL Kota Pontianak. Kondisi konda adalah suatu kondisi dimana air tidak mengalami pasang dan tidak surut, lihat Gambar 6. Dan pada saat kondisi hujan pengukuran di lapangan dilakukan pada tanggal 21 Mei 2012, lihat Gambar 7 Data pasang surut yang di dapat dari TNI- AL Kota Pontianak untuk bulan Mei dapat dilihat pada gambar 8.

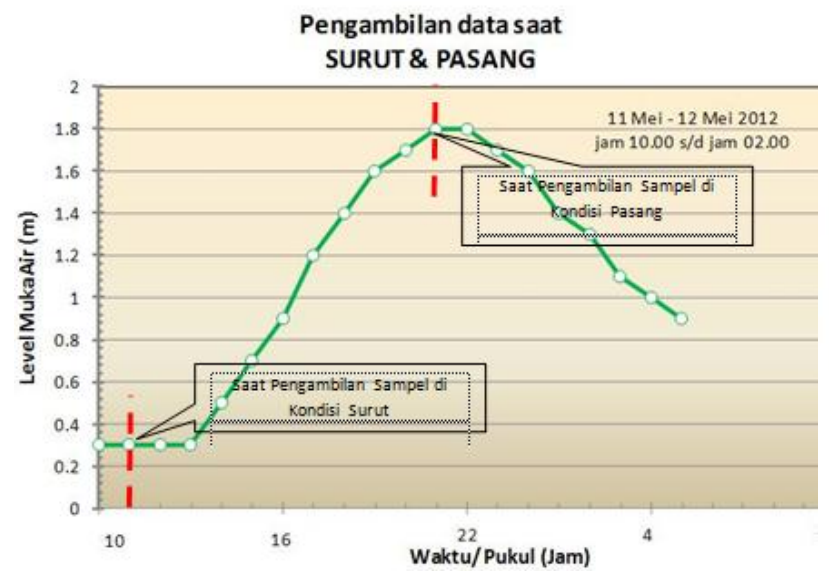

Gambar 6. Pengambilan Data Saat Surut dan Pasang

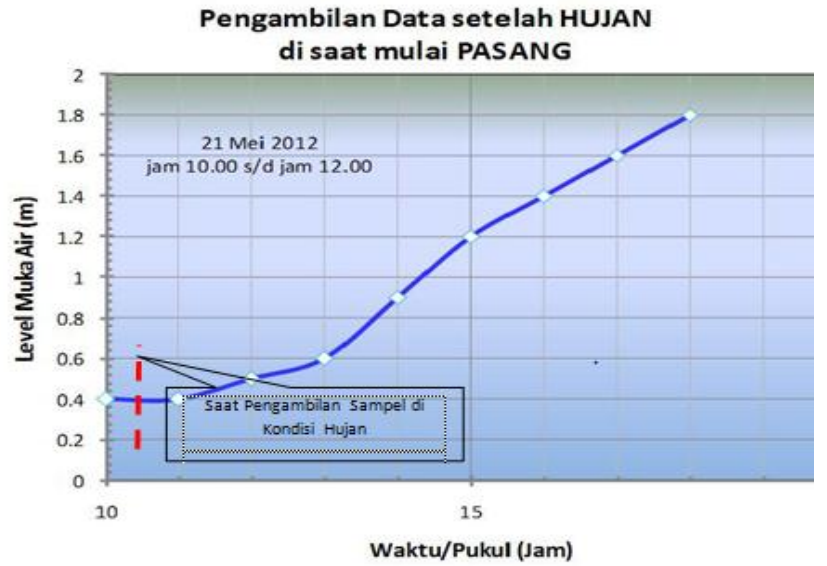

Gambar 7. Pengambilan Data Setelah Hujan 


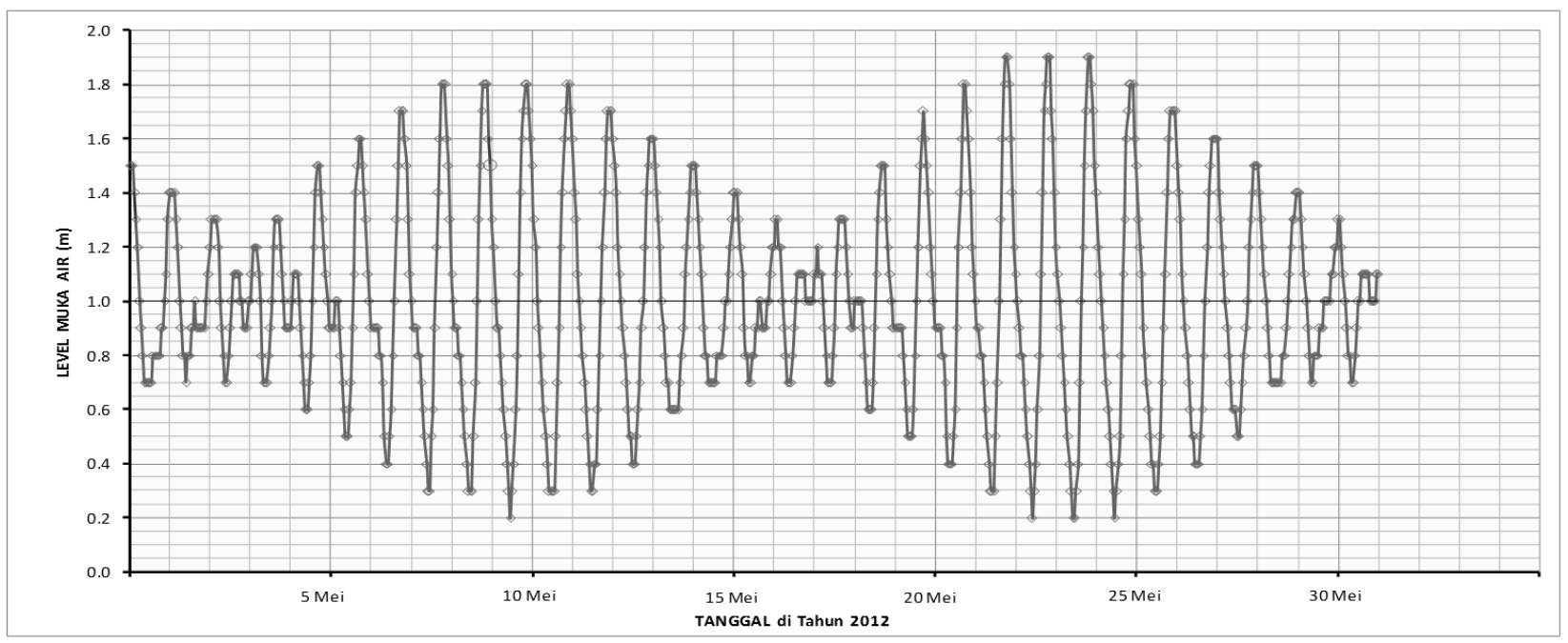

Gambar 8. Ramalan Data Pasang Surut

Perhitungan debit sederhana ini telah menggambarkan ketersediaan air Sungai Jawi untuk kedepannya. Pengukuran kecepatan dan luas penampang sungai dilakukan langsung di lapangan.

$$
\boldsymbol{Q}=\boldsymbol{V} \cdot \boldsymbol{A}
$$

dimana,

$Q=$ debit air

$V=$ kecepatan air terukur di lapangan $(v=0,1 \mathrm{~m} / \mathrm{s})$

$A=$ luas penampang terukur di lapangan ( kedalaman sungai $(p)=1,20 \mathrm{~m}$ dan lebar sungai $(I)=14 \mathrm{~m}$ )

Penyelesaian :

$Q=V \times A$

$Q=V \times(P \times L)$

$Q=0,1 \mathrm{~m} /$ detik $\times(14 \mathrm{~m} \times 1,20 \mathrm{~m})$

$Q=1,68 \mathrm{~m}^{3} /$ detik $=1680 \mathrm{~L} /$ detik

Dengan demikian didapatlah debit air Sungai Jawi sebesar 1680 L/detik, cukup untuk memenuhi kebutuhan air bersih enam desa yang akan dilayani dari tahun awal (156,89 L/detik) dan pada akhir tahun perencanaan 2030 (306,56 L/detik). Kebutuhan air ini, $\pm 20 \%$ dari debit yang ada di sungai.

\section{Rancangan Bangunan Bendungan (Long Storage)}

Untuk meminimalisasikan aliran rambatan salinitas pada lokasi intake terpilih, maka akan dilakukan upaya dengan membuat bendungan atau disebut juga dengan sistem long storage, sistem ini seperti bendungan yang juga akan memenuhi kebutuhan air keenam desa dalam satu hari selama 8 jam. Perhitungan panjang, lebar dan tinggi tanggul sungai terhadap debit air yang diperlukan dapat dilihat pada Tabel 3.

Tabel 3. Perhitungan Panjang, Lebar dan Tinggi Tanggul Sungai

\begin{tabular}{|c|c|c|c|c|}
\hline Liter & $\mathrm{m}^{2}$ & Panjang $(\mathrm{m})$ & Lebar $(\mathrm{m})$ & Tinggi $(\mathrm{m})$ \\
\hline $21.789 .177,7$ & $21.785,18$ & 2.500 & 15 & 0,6 \\
\hline $30.000 .000,0$ & $30.000,00$ & 2.500 & 15 & 0,8 \\
\hline $38.124 .060,9$ & $38.124,06$ & 2.500 & 15 & 1,02 \\
\hline
\end{tabular}

Mengingat kebutuhan air yang harus dipenuhi sampai pada tahun perencanaan akhir 2030 adalah 306,56 L/detik atau 26.487.148,17 Liter/hari, maka dari tabel 3 di atas, dapat dipilih perhitungan nomor ketiga dengan panjang bendungan $2.500 \mathrm{~m}$, lebar $15 \mathrm{~m}$ serta tinggi bendungan 1,02 $\mathrm{m}$, debit yang dapat ditampung sebanyak 38.124.060,91 Liter/hari. Panjang bendungan akan dimulai dari lokasi A3 sampai A4. Setelah diperoleh panjang, lebar serta tinggi bendungan yang akan dibangun, maka akan dibuat sistem intake . 


\section{Kesimpulan}

Lokasi intake terbaik/terpilih berada di lokasi $\mathrm{A} 3$ berdasarkan nilai salinitas terendah yang diperoleh dari hasil penelitian, yaitu $0,00 \%$, baik pada saat pasang, surut maupun hujan. Dengan jarak lokasi dari Parit Haruna (A1) sejauh $3 \mathrm{~km}$ sedangkan dari muara Kakap jaraknya sejauh 10,22 km masih dalam kategori air tawar. Nilai DO pada saat pasang, surut dan hujan berturut turut 4,23; 3,53; 5,42. Nilai Kekeruhan (NTU) pada saat pasang, surut dan hujan berturut-turut 47; 29,93; 70,73. Nilai pH pada saat pasang, surut dan hujan berturut-turut 6,$4 ; 6,3 ; 5,7$. Nilai Suhu $\left({ }^{\circ} \mathrm{C}\right)$ pada saat pasang, surut dan hujan berturut-turut $31 ; 28 ; 25$. Parameter ini belum memenuhi syarat Baku Mutu Air Baku Kelas I dan memerlukan pengolahan air untuk menjadi air bersih.

Debit air yang diperlukan untuk memenuhi kebutuhan air penduduk keenam desa, Kecamatan Sungai Kakap pada tahun 2030 adalah sebesar 306,56 L/det dengan debit air Sungai Jawi sebesar $1680 \mathrm{~L} /$ det $( \pm 20 \%$ dari debit yang tersedia), cukup untuk memenuhi kebutuhan air bersih keenam desa dengan jumlah penduduk sebanyak 96.160 jiwa.

Untuk menahan rambatan salinitas aliran air Sungai Jawi pada lokasi intake terpilih, maka akan dilakukan upaya dengan membuat waduk atau disebut juga dengan sistem long storage. Sistem ini juga akan memenuhi kebutuhan air penduduk dalam satu hari selama 8 jam. Dengan panjang waduk $2.500 \mathrm{~m}$, lebar $15 \mathrm{~m}$ serta tinggi waduk 1,02 m, debit yang dapat ditampung sebanyak 38.124.060,91 L.

\section{Ucapan Terima Kasih}

Penulis mengucapkan terima kasih yang sebesar-besarnya kepada kedua orang tua $\mathrm{H}$. Kusnadi dan $\mathrm{Hj}$. Erlita Kurmala Devi atas doa, moril dan materil. Penulis juga mengucapkan kepada bapak Dr. Ir. Johnny MTS, M.Sc dan bapak H. Kiki Prio Utomo ST, M.Sc selaku dosen pembimbing dalam penelitian ini. Tidak lupa saya ucapkan banyak terima kasih kepada Laboratorium Analisis Lingkungan, Fakultas Pertanian yang telah membantu penulis dalam penelitian ini.

\section{Daftar Pustaka}

Badan Pusat Statistik. 2011. Kecamatan Sungai Kakap Dalam Angka Tahun 2011.

Ditjen Cipta Karya Departemen Pekerja Umum. 2000. Tentang Kriteria Perencanaan Air Bersih.

Effendi, H., 2003. Telaah Kualitas Air Bagi Pengolahan Sumberdaya Hayati Lingkungan Perairan. Yogyakarta: Kanysius.

KEPMENKES Republik Indonesia Nomor: 416/MENKES/PER/IX/1990. Tentang Syarat-Syarat dan Pengawasan Kualitas Air.

NSPM Kimpraswil . 2002. Pedoman Petunjuk Teknis Manual. Vol. 6 (II dan III).

Peraturan Pemerintah Republik Indonesia No. 82 tahun 2001. Tentang Pengelolaan Kualitas Air dan Pengendalian Pencemaran Air. 